\title{
ARTIGO CIENTIFICO
}

\section{Substituição parcial do potássio por sódio na adubação do capim mombaça em ciclos de pastejo}

\author{
Partial replacement of potassium by sodium in the fertilization of Mombasa in grazing \\ cycles
} Carlos Augusto Oliveira de Andrade ${ }^{1}$, Rodrigo Ribeiro Fidelis ${ }^{2}$, Antônio Clementino dos Santos ${ }^{3}$, Antônio Carlos Martins dos
Santos $^{4}$, Rubens Ribeiro da Silva $^{5}$

Resumo - Este estudo teve como objetivo avaliar o efeito da substituição parcial do potássio por sódio na adubação do capim Panicum maximum cv. Mombaça em dois ciclos de pastejo. O delineamento experimental utilizado foi o inteiramente casualizado em esquema fatorial $2 \times 4+1$, com três repetições. O primeiro fator foi constituído por dois ciclos de pastejo $(60$ e 90 dias após a emergência das plantas) o segundo por quatro doses de $\mathrm{Na}^{+}$em substituição ao $\mathrm{K}^{+}(0+80,20+60,40+40$ e $60+20$ $\mathrm{mg} \mathrm{dm}{ }^{-3}$ de $\mathrm{Na}^{+}+\mathrm{K}^{+}$, respectivamente) e o tratamento adicional foi constituído pelo solo sem adubação. Foi observado que o uso de $\mathrm{Na}^{+}$em substituição ao $\mathrm{K}^{+}$na adubação do capim Mombaça resultou no decréscimo da altura de plantas, índice de clorofila, massa verde da parte aérea, massa seca da parte aérea e número de perfilhos em ambos os ciclos de pastejo. O segundo ciclo de pastejo proporciona maiores médias nos indicadores índice de clorofila, número de perfilhos, massa verde da parte aérea e massa seca da parte aérea quando comparado ao primeiro ciclo. A substituição do $\mathrm{K}^{+}$por $\mathrm{Na}^{+}$na adubação aumenta a produção de forragem até a dose de $28,77 \mathrm{mg} \mathrm{dm}^{-3} \mathrm{de} \mathrm{Na}^{+}$a partir dos 60 dias de emergência das plantas. A substituição do $\mathrm{K}^{+}$por $\mathrm{Na}^{+}$na adubação reduz em 7,9\% o desenvolvimento do capim Mombaça.

Palavras-chave: forrageira, salinidade, fonte alternativa

\begin{abstract}
This study aimed to evaluate the effect of partial replacement of potassium by sodium fertilization of Panicum maximum cv. Mombasa in two grazing cycles. The experimental design was a completely randomized factorial $2 \times 4+1$ with three replications. The first factor was composed of two cutting times (60 and 90 days after emergence) the second of four doses of $\mathrm{Na}^{+}$in place of $\mathrm{K}^{+}\left(0+80,20+60,40+40\right.$ and $60+20 \mathrm{mg} \mathrm{dm}^{-3} \mathrm{Na}^{+}+\mathrm{K}^{+}$, respectively) and additional treatment was constituted by absence of soil fertilization. It was observed that the use of $\mathrm{Na}^{+}$to replace $\mathrm{K}^{+}$in the fertilization of the grass Mombasa resulted in decreased plant height, chlorophyll content, fresh weight of shoot, dry shoot and tiller number in both grazing cycles. The second grazing cycle provides higher averages in indicators chlorophyll index, tiller number, fresh weight of shoot and root and shoot dry mass compared to the first cycle. Replacement of $\mathrm{K}^{+}$by $\mathrm{Na}^{+}$in fertilization increased forage production up to a dose of $28.77 \mathrm{mg} \mathrm{dm}^{-3} \mathrm{Na}^{+}$from 60 days after emergence of the plants. Replacement of $\mathrm{K}^{+}$by $\mathrm{Na}^{+}$in fertilization reduces by $7.9 \%$ the development of grass Mombasa.
\end{abstract}

Keywords: forager, salinity, alternative source

\section{Autor para correspondência}

Recebido em 30/11/2014 aceito em 15/12/2014

${ }^{1}$ Mestrando em Produção Vegetal - Universidade Federal do Tocantins, Caixa postal 66, Rua Badejós, chácaras 69 e 72, Lt.07. Gurupi-TO. E-mail: carlosandradeuft@hotmail.com

${ }^{2}$ Professor Adjunto - Universidade Federal do Tocantins, Caixa postal 66, Rua Badejós, chácaras 69 e 72, Lt.07. Gurupi-TO. E-mail: fidelisrr@uft.edu.br

${ }^{3}$ Professor Adjunto - Universidade Federal do Tocantins, Caixa postal 66, Rua Badejós, chácaras 69 e 72, Lt.07. Gurupi-TO. E-mail: clementino@uft.edu.br

${ }^{4}$ Mestrando em Produção Vegetal - Universidade Federal do Tocantins, Caixa postal 66, Rua Badejós, chácaras 69 e 72, Lt.07. Gurupi-TO. E-mail:

${ }^{5}$ Professor Adjunto - Universidade Federal do Tocantins, Caixa postal 66, Rua Badejós, chácaras 69 e 72, Lt.07. Gurupi-TO. E-mail: rrs2002@uft.edu.br 


\section{INTRODUÇÃO}

O Brasil é um dos maiores consumidores de fertilizantes do mundo. Estima-se que mais de $75 \%$ dos fertilizantes consumidos no país vem do exterior. No caso do Potássio $\left(\mathrm{K}^{+}\right) 91 \%$ são importados, pois a produção interna satisfaz pouco mais do que $10 \%$ da demanda, sendo necessária a importação de grandes volumes a custo superior de US\$ 600 milhões ano ${ }^{-1}$ (DUARTE et al., 2012).

Dentre as fontes de $\mathrm{K}^{+}$, o Cloreto de Potássio $(\mathrm{KCl})$ é o fertilizante mais utilizado na agricultura brasileira por causa da alta concentração de $\mathrm{K}_{2} \mathrm{O}(58$ a $62 \%)$ e devido ao menor custo por unidade de $\mathrm{K}^{+}$(YAMADA \& ROBERTS, 2005). Segundo Lopes (2005), a única fonte produtora de fertilizantes potássicos no Brasil é o complexo de Mina/Usina de Taquari-Vassouras, em Sergipe, que vem sendo explorado pela Companhia Vale do Rio Doce desde o final de 1991.

$\mathrm{O} \mathrm{K}^{+}$é o segundo nutriente mineral mais requerido pelas plantas. Os teores de $\mathrm{K}^{+}$para bom desenvolvimento das forrageiras variam entre 20 e $50 \mathrm{~g} \mathrm{~kg}^{-1}$ de massa seca do vegetal. Esse nutriente é necessário para a fotossíntese, e, em situações de deficiência, provoca redução da taxa fotossintética e aumento na respiração, resultando na diminuição do acúmulo de carboidratos. Além disso, desempenha várias funções, como ativação de diversos sistemas enzimáticos, o que aumenta a resistência à salinidade, geada, seca, doenças e melhora a qualidade da forragem (ERNANI et al., 2007).

Assim, frente a fatores como a alta dependência de importações desse nutriente, a deficiência nos solos brasileiros e a demanda por produtos que contenham o $\mathrm{K}^{+}$, constatam-se a importância em se desenvolver pesquisas por fontes alternativas mais econômicas.

Muitas pesquisas têm identificado $\mathrm{o} \mathrm{Na}^{+}$para diferentes culturas como um dos responsáveis por desequilíbrios nutricionais, afetando a disponibilidade na absorção dos nutrientes e causando inativação fisiológica em alguns deles (VILLORA et al., 1997). Embora, existam estudos que mostram que o $\mathrm{Na}^{+}$e o $\mathrm{K}^{+}$compartilham algumas funções fisiológicas. Os primeiros estudos em algodão indicaram que o $\mathrm{Na}^{+}$pode substituir parcialmente o $\mathrm{K}^{+}$na dose de $65 \mathrm{mg} \mathrm{kg}$ ${ }^{1}$ de solo (ZHANG et al., 2006). Pesquisas têm demonstrado que a substituição parcial do $\mathrm{K}^{+}$com $\mathrm{Na}^{+}$pode melhorar a produção de algumas culturas, incluindo a da beterraba (Beta vulgaris), do tomate (Lycopersicum esculentum), do arroz (Oryza sativa) (HOHJO et al., 2001; ZHANG et al., 2006).

Em forrageiras como o capim Mombaça ainda são poucas as informações quanto ao uso do $\mathrm{Na}^{+}$, quanto à sua classificação como elemento essencial e aos níveis críticos do elemento no solo e na planta. Contudo, por ser planta $\mathrm{C}_{4}$, o $\mathrm{Na}^{+}$pode apresentar potencial para o uso como fertilizante, pois nessas espécies $\mathrm{o} \mathrm{Na}{ }^{+}$exerce função na regeneração do fosfoenol piruvato (PEP), conforme foi observado em Amaranthus tricolor por Ohta et al. (1987). Ademais, Marschner (1995) relata que em muitos vegetais $\mathrm{C}_{4}, \mathrm{o} \mathrm{Na}^{+}$ tem sido reportado como participante da síntese de clorofila e sua deficiência tem sido relatada por prejudicar a conversão de piruvato ao PEP.

Considerando que a fertilização com $\mathrm{K}^{+}$é prática comumente usada em diversas culturas plantadas no Cerrado como as forrageiras e que, resposta ao $\mathrm{Na}^{+}$tem sido observadas em ambientes pobres em potássio (LACLAU et al., 2003), a busca por pesquisas que evidenciam a influência desses nutrientes no desenvolvimento de forrageiras se torna importante para o manejo técnico e economicamente viável em pastagens.

Nesse sentido, objetivou-se com este trabalho avaliar o efeito da substituição parcial do Potássio por Sódio na adubação do capim Panicum maximum cv. Mombaça em dois ciclos de pastejo.

\section{MATERIAL E MÉTODOS}

O trabalho foi conduzido na área experimental da Universidade Federal do Tocantins (UFT), Campus Universitário de Gurupi, em casa de vegetação. A área está localizada nas coordenadas $11^{\circ} 43^{\prime} 45^{\prime \prime}$ de latitude e $49^{\circ} 04^{\prime} 07^{\prime}$ ' de longitude, a $280 \mathrm{~m}$ de altitude no sul do estado do Tocantins.

Como substrato foi utilizado solo da camada de 0 a $20 \mathrm{~cm}$ de Latossolo Vermelho-Amarelo distrófico textura média (EMBRAPA, 2006). O solo coletado foi preparado como Terra Fina Seca ao Ar. Após esse procedimento foi realizada a caracterização física e química do solo, a qual apresentou os seguintes resultados: $\mathrm{pH}$ em $\mathrm{CaCl}_{2}=5,50 ; \mathrm{P}=8,49 \mathrm{mg} \mathrm{dm}^{-3}$; $\mathrm{K}=23,58 \mathrm{mg} \mathrm{dm}^{-3} ; \mathrm{Ca}=2,24 \mathrm{cmol}_{\mathrm{c}} \mathrm{dm}^{-3} ; \mathrm{Mg}=0,46 \mathrm{cmol}_{\mathrm{c}}$ $\mathrm{dm}^{-3} ; \mathrm{Al}=0,0 \mathrm{cmol}_{\mathrm{c}} \mathrm{dm}^{-3} ; \mathrm{H}+\mathrm{Al}=1,53 \mathrm{cmol}_{\mathrm{c}} \mathrm{dm}^{-3} ; \mathrm{SB}=$ $2,76 \mathrm{cmol}_{\mathrm{c}} \mathrm{dm}^{-3} ; \mathrm{CTC}=4,29 \mathrm{cmol}_{\mathrm{c}} \mathrm{dm}^{-3} ; \mathrm{V}=64,27 \% ;$ M.O. $=16,70 \mathrm{~g} \mathrm{dm}^{-3} ;$ Areia $=62,8 \% ;$ Silte $=8,83 \%$ e Argila $=$ $28,33 \%$

Após a caracterização foi verificado que o solo já apresentava valores de saturação de base acima de $60 \%$ e pH em água superior a 5,5. Por esse motivo não foi realizada a calagem, uma vez que o solo já atendia a demanda da cultura (CANTARUTTI et al., 1999).

A adubação do solo para o preparo do substrato foi constituída de uréia como fonte de $\mathrm{N}$, superfosfato simples como fonte de P e FTE BR-12 como fonte de micronutrientes nas doses de 277,1000 e $125 \mathrm{mg} \mathrm{dm}^{-3}$, respectivamente. Os adubos e o solo foram colocados em sacos plásticos individuais. Após esse procedimento foi realizada 45 revoluções por período de um minuto para garantir a incorporação de forma homogênea em todos os tratamentos.

As doses dos fertilizantes foram calculadas a partir da análise química do solo sendo adubação de estabelecimento para médio nível tecnológico conforme o Manual de quinta aproximação do estado de Minas Gerais (CANTARUTTI et al., 1999). As doses calculadas foram aumentadas em cinco vezes conforme recomendado por Eichler et al. (2008).

A parcela experimental foi constituída por vasos plásticos com capacidade para $5,0 \mathrm{dm}^{3}$, que receberam $4,0 \mathrm{dm}^{3}$ do substrato. Em cada vaso foram realizados cinco furos nas laterais de forma assegurar a reposição da água ao nível da capacidade de campo.

$\mathrm{O}$ delineamento experimental utilizado foi o inteiramente casualizado em esquema fatorial $2 \times 4+1$, com três repetições. O primeiro fator foi constituído por dois ciclos de pastejo (60 e 90 dias após a emergência das plantas); o segundo por quatro doses de $\mathrm{Na}^{+}$em substituição ao $\mathrm{K}^{+}(0+80,20+60$, $40+40$ e $60+20 \mathrm{mg} \mathrm{dm}^{-3} \mathrm{de}^{+} \mathrm{Na}^{+} \mathrm{K}^{+}$, respectivamente) e, o tratamento adicional foi constituído pelo solo sem adubação.

A forrageira utilizada foi a gramínea Panicum maximum Jacq. cv. Mombaça, cujas sementes apresentaram as seguintes características: pureza $=62 \%$, germinação $=82 \%$ e valor 
cultural $=50 \%$. A semeadura foi realizada em cada vaso, com auxílio de limitador com diâmetro inferior ao do vaso. Assim foi demarcado círculo distando $5 \mathrm{~cm}$ da lateral do vaso com $1,0 \mathrm{~cm}$ de profundidade. $\mathrm{Na}$ área do círculo foram semeadas $2,0 \mathrm{~g}$ de sementes em cada vaso.

Após a semeadura, os vasos foram irrigados de forma a atingir a capacidade de campo do substrato (considerou-se que o solo encontrava-se na capacidade de campo, quando, após a irrigação, ocorria o início do gotejamento no furo localizado no fundo do vaso plástico). As irrigações subseqüentes foram feitas diariamente às 11 horas da manhã.

Aos 10 dias após a emergência das plantas foi realizado o desbaste, deixando-se sete plantas bem distribuídas por vaso, sendo mantida essa população por vaso. Já aos 30 dias após a emergência das plantas foi realizado corte de uniformização, efetuado a $20 \mathrm{~cm}$ de altura a partir da superfície do solo. Além do corte de uniformização, realizaram-se mais dois cortes simulando ciclos de pastejo, para fins de avaliações (a $20 \mathrm{~cm}$ de altura) a cada trinta dias.

Aos 60 dias após a germinação, efetuou-se adubação de cobertura, aplicando-se $277 \mathrm{mg} \mathrm{dm}^{-3}$ de $\mathrm{N}$ na forma de uréia (CANTARUTTI et al., 1999).

Os indicadores morfológicos para a avaliação do desenvolvimento da forrageira foram: altura de planta obtida após o corte de uniformização, medindo do solo até o ápice da planta com o auxílio de trena metálica, semanalmente; taxa de crescimento da planta calculada pela relação da altura média das plantas e o número de dias de cada ciclo de pastejo; índice de clorofila expressos em unidade denominada Índice de Clorofila Falker (ICF), resultante de unidades adimensionais existentes nas folhas, utilizando-se método indireto, por meio de leitura efetuada em aparelho clorofilômetro ClorofiLOG ${ }^{\circledR}$, modelo CFL 1030, semanalmente; massa verde da parte aérea, o material coletado em cada corte de avaliação foi pesado no momento do corte em balança de precisão; massa

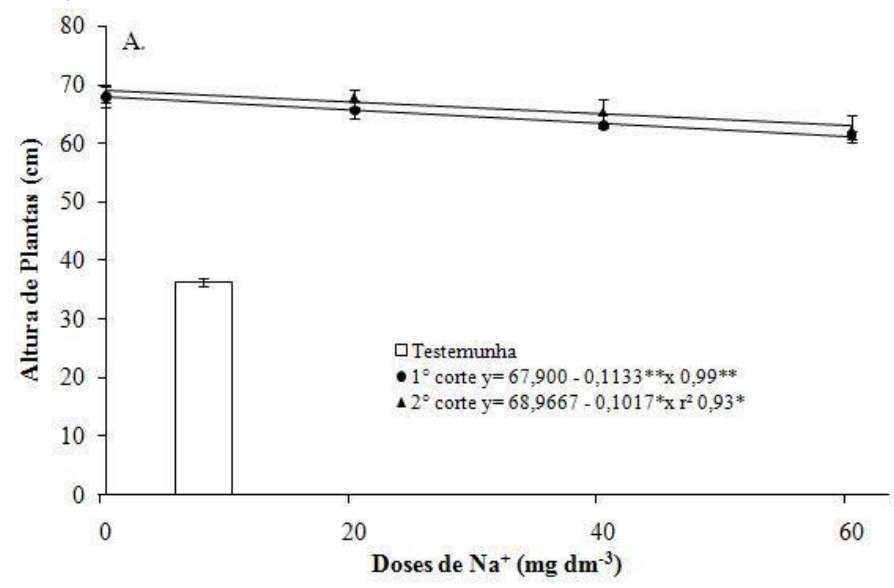

seca da parte aérea, o material passou por processo de secagem em estufa com circulação forçada de ar, a $60{ }^{\circ} \mathrm{C}$ durante 72 horas, após a secagem procedeu-se à pesagem da massa verde da parte aérea em balança de precisão; número de perfilhos, após cada corte de avaliação, contaram-se os perfilhos totais presentes em cada vaso.

Os resultados obtidos foram submetidos às análises de variância e utilização de regressão através do programa SigmaPlot 10. Os modelos de regressão foram escolhidos baseados na significância dos coeficientes da equação de regressão e no coeficiente de determinação, adotando-se 1 e $5 \%$ de probabilidade.

\section{RESULTADOS E DISCUSSÃO}

A substituição do $\mathrm{K}^{+}$por $\mathrm{Na}^{+}$na adubação do capim Mombaça, resultou no decréscimo linear do crescimento das plantas em ambos os ciclos de pastejo (Figura 1A e 1B). Na altura de plantas as doses de 20, 40 e $60 \mathrm{mg} \mathrm{dm}^{-3} \mathrm{de} \mathrm{Na}^{+}$ foram responsáveis pelas reduções de 3,4, 7,3 e 9,8\% no primeiro ciclo e $1,3,9$ e $8,8 \%$ no segundo ciclo, respectivamente (Figura 1A). Na taxa de crescimento (Figura 1B), as doses de 20,40 e $60 \mathrm{mg} \mathrm{dm}^{-3}$ de $\mathrm{Na}^{+}$foram responsáveis pelas reduções de $3,5,7,0$ e $9,7 \%$ no primeiro e $1,3,4,8$ e $8,8 \%$ no segundo ciclo, respectivamente. Dessa

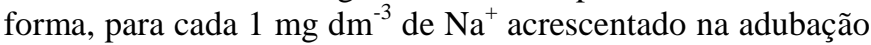
em substituição ao $\mathrm{K}^{+}$houve redução na taxa de crescimento da planta de 0,0038 e 0,0034 cm no primeiro e segundo ciclos de pastejo, respectivamente. Efeito negativo no crescimento de plantas submetidas ao estresse salino também foram verificados por Romero (2008), que estudando resposta fisiológica de plantas de Eucalyptus grandis à adubação com $\mathrm{K}^{+}$ou $\mathrm{Na}^{+}$, observaram que o aumento do $\mathrm{Na}^{+}$na adubação reduziu o incremento em altura de plantas em $2,35 \mathrm{~cm}$ em 30 dias.

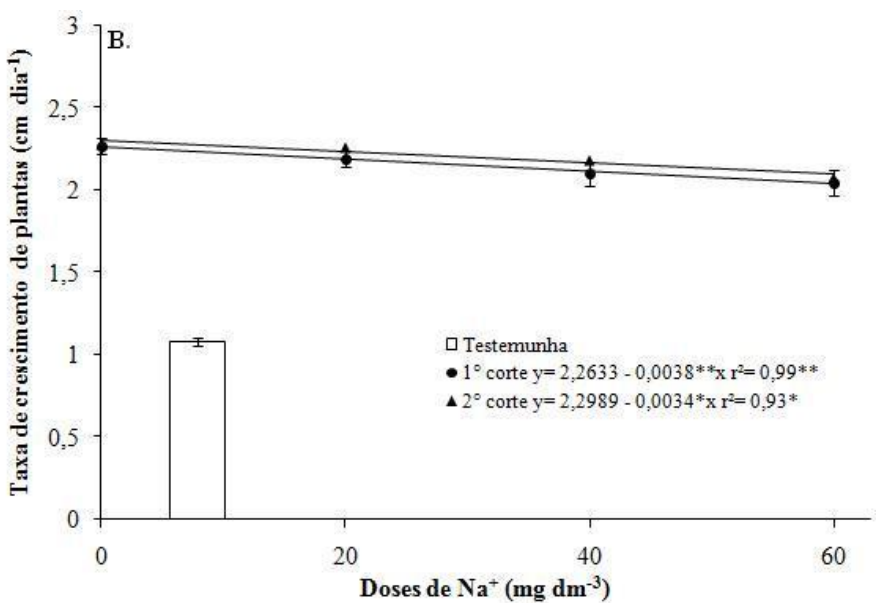

Figura 1. Altura de plantas (A) e Taxa de crescimento de plantas (B) de capim Panicum maximum cv. Mombaça em função da substituição parcial do Potássio $\left(\mathrm{K}^{+}\right)$pelo Sódio $\left(\mathrm{Na}^{+}\right)$em ciclos de pastejo. Gurupi-TO, 2013

Os efeitos da salinização sobre as plantas podem ser causados pelas dificuldades de absorção de água, toxicidade de íons específicos e pela interferência dos sais nos processos fisiológicos (CAVALCANTE et al., 2010). Incrementos na concentração de $\mathrm{NaCl}$ na solução do solo prejudicam a absorção de nutrientes e interferem nas suas funções fisiológicas, reduzindo o crescimento e o desenvolvimento das plantas (ARAGÃO et al., 2010).
$\mathrm{O}$ índice de clorofila presente nas folhas do capim Mombaça sob o efeito de doses de $\mathrm{Na}^{+}$em substituição ao $\mathrm{K}^{+}$ apresentou redução linear em ambos os ciclos (Figura 2). As doses de 20, 40 e $60 \mathrm{mg} \mathrm{dm}^{-3}$ de $\mathrm{Na}^{+}$foram responsáveis pelas reduções de 3,1, 3,9 e 9,7\% no primeiro e 3,6, 3,9 e 9\% no segundo ciclo, respectivamente. Isso mostra, que o aumento das doses de $\mathrm{Na}^{+}$em substituição ao $\mathrm{K}^{+}$na adubação, pode ter inibido a absorção de $\mathrm{K}^{+}$pela planta, visto que, o potássio participa da estrutura do cloroplasto, na 
translocação de assimilados (sacarose), e há indícios de que o armazenamento nos tecidos de plantas considerados como dreno depende que as concentrações de $\mathrm{K}^{+}$no tecido estejam adequados (TALBOTT \& ZEIGER, 1998). Segundo Aragão et al. (2010), quando o conteúdo de $\mathrm{NaCl}$ no solo é alto, a absorção de nutrientes minerais, especialmente o $\mathrm{NO}^{3-}, \mathrm{K}^{+}$e $\mathrm{Ca}^{2+}$ é reduzida pela planta afetando o seu desenvolvimento.

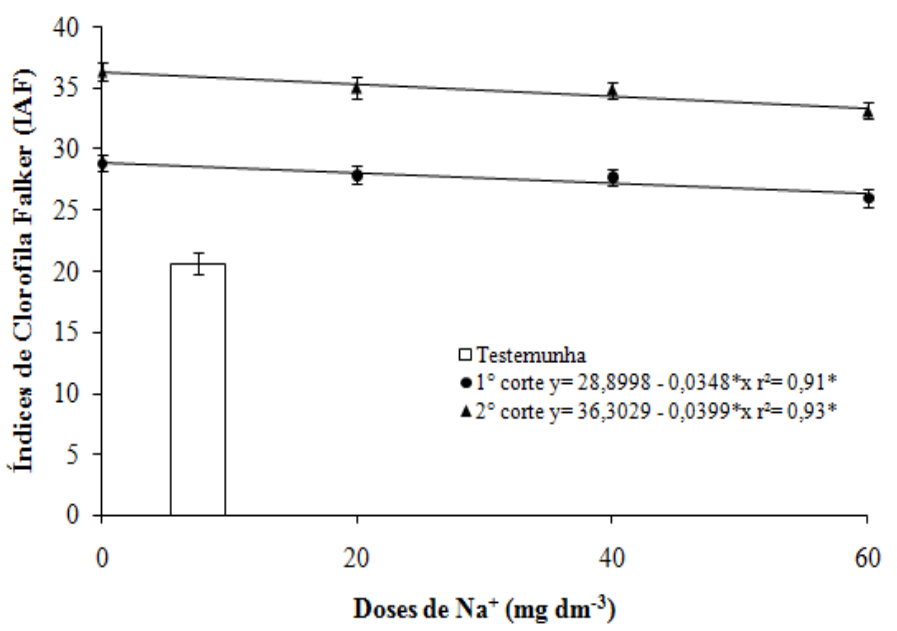

Figura 2. Índice de clorofila de capim Panicum maximum cv. Mombaça em função da substituição parcial do Potássio $\left(\mathrm{K}^{+}\right)$ pelo Sódio $\left(\mathrm{Na}^{+}\right)$em ciclos de pastejo. Gurupi-TO, 2013

Efeito negativo nos teores de clorofila em plantas submetidas ao estresse salino também foram verificados por Lacerda et al. (2006), que estudando efeitos da salinidade na cultura da Vigna unguiculata, observaram que os níveis de salinidade reduziram os teores de clorofila, sugerindo que essas mudanças podem constituir parte de processo integrado de adaptação da planta ao estresse salino.

Quanto ao efeito de corte na produção de clorofila, foi observado que o segundo corte apresentou produção superior ao primeiro corte em todas as doses. Nas doses 0,20 e $40 \mathrm{mg}$ $\mathrm{dm}^{-3}$ de $\mathrm{Na}^{+}$em substituição ao $\mathrm{K}^{+}$, esse aumento foi de $20,6 \%$ e na dose $60 \mathrm{mg} \mathrm{dm}^{-3}$ esse aumento foi de $21,4 \%$, respectivamente. Isso pode ser explicado pela redução dos teores de $\mathrm{Na}^{+}$no substrato, ocasionado por extrações feitas pela planta nos primeiros 60 dias de emergência, o que resultou na diluição da salinidade no substrato proporcionando melhor resposta da planta. Nesse sentido, a salinidade do solo contribui para a redução dos teores de clorofila na planta e conseqüente redução da fotossíntese, devido à diminuição da disponibilidade de $\mathrm{CO}_{2}$ no interior das folhas, pelo fechamento dos estômatos, o que acarreta

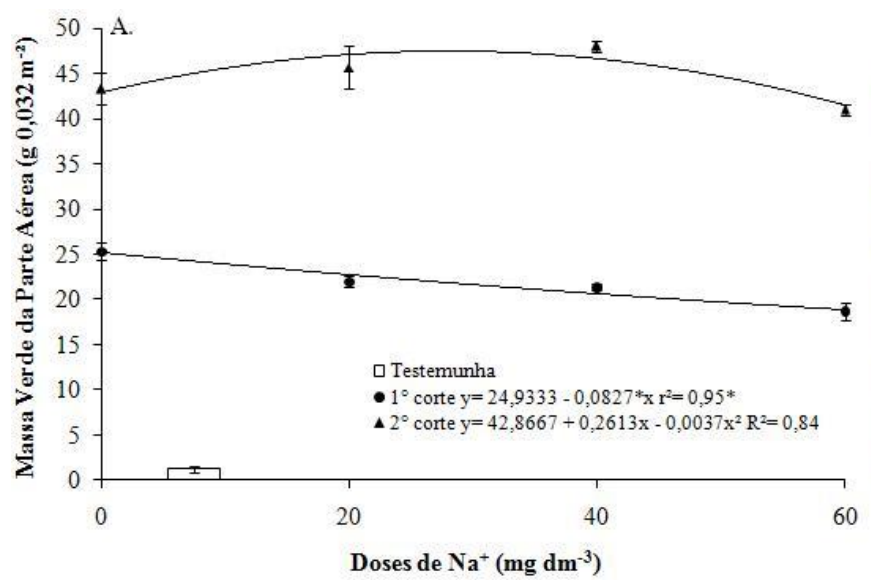

série de efeitos acumulativos, que geram menor produção de fotoassimilados nas folhas, e por consequiência a produção de biomassa (SULTANA et al., 1999).

$\mathrm{Na}$ produção de forragem avaliada pelos indicadores massa verde da parte aérea (Figura 3A) e massa seca da parte aérea (Figura 3B), o aumento das doses de $\mathrm{Na}^{+}$em substituição ao $\mathrm{K}^{+}$na adubação do capim Mombaça, alterou a produtividade dos indicadores promovendo diferentes respostas entre os ciclos de pastejo. No primeiro ciclo o indicador massa verde da parte aérea e massa seca da parte aérea apresentaram redução linear em função do aumento das doses de $\mathrm{Na}^{+}$substituindo o $\mathrm{K}^{+}$. Efeito negativo na produtividade de matéria seca em plantas submetidas ao estresse salino também foram verificadas por Dantas et al. (2006) estudando diferentes teores de $\mathrm{Na}^{+}$sobre o crescimento e composição mineral de seis clones de Pennisetum, notaram redução de até $77 \%$ da biomassa fresca e seca com o aumento dos teores de sódio. Reduções significativas da matéria seca da parte aérea de $79 \%$ de mudas de goiabeira foram constatadas por Ferreira et al. (2001), aos 50 dias sob estresse salino de $150 \mathrm{mmol} \mathrm{L}^{-1}$ de $\mathrm{NaCl}$.

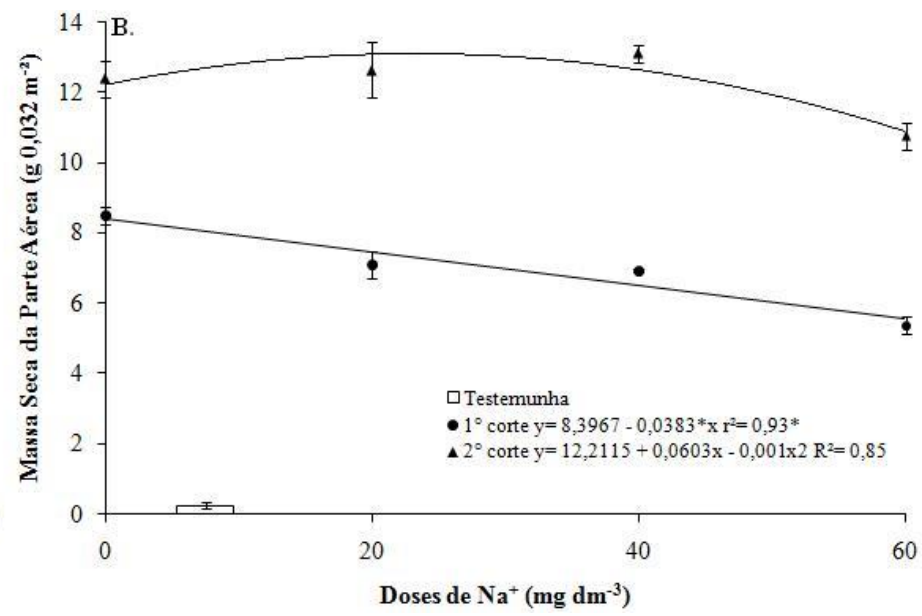

Figura 3. Massa verde da parte aérea (A) e Massa seca da parte aérea (B) de capim Panicum maximum cv. Mombaça em função da substituição parcial do Potássio $\left(\mathrm{K}^{+}\right)$pelo Sódio $\left(\mathrm{Na}^{+}\right)$em ciclos de pastejo. Gurupi-TO, 2013 
As reduções e, ou, inibições constatadas no crescimento dos vegetais, à medida que são submetidos a concentrações crescentes de salinidade, podem ser atribuídas ao efeito osmótico, à toxicidade pela absorção excessiva dos íons $\mathrm{Na}^{+} \mathrm{e}$ $\mathrm{Cl}^{-}$e ao desequilíbrio nutricional causado pelos distúrbios na absorção dos nutrientes essenciais. No entanto, algumas plantas possuem isoenzimas que estão relacionadas com a adaptação às condições salinas, promovendo melhor desenvolvimento em relação as não adaptadas (SILVA et al., 2009).

No segundo ciclo os resultados de massa verde da parte aérea (Figura 3A) e massa seca da parte aérea (Figura 3B) apresentaram resposta quadrática. $\mathrm{O}$ aumento nas doses de

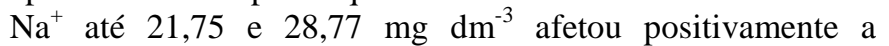
produtividade de massa seca da parte aérea e massa verde da parte aérea, respectivamente. Isso mostra possível benefício do $\mathrm{Na}^{+}$na adubação do capim Mombaça com o aumento até $28,77 \mathrm{mg} \mathrm{dm}^{-3}$ de $\mathrm{Na}^{+}$, tendo em vista que a dose zero de $\mathrm{Na}^{+}$ apresentou valores menores em produção de forragem no segundo ciclo. O mesmo comportamento foi observado por Fernades et al. (2003), que trabalhando com diferentes níveis de salinidade em Pupunheira (Bactris gasipaes H.B.K) afirmaram que o tratamento zero de $\mathrm{Na}^{+}$afetou mais a produtividade da planta do que aquele representado por 110 $\mathrm{mg} \mathrm{L}^{-1}$ de $\mathrm{Na}^{+}$. Contudo, Silva et al. (2010) em estudo avaliando as alterações nos teores trocáveis e na saturação de $\mathrm{Na}^{+}$no complexo de troca, em solo cultivado com capim Tifton 85 submetido à aplicação de percolado de resíduo sólido urbano em diferentes taxas, não encontraram perda de produtividade quando se aplicou altas doses de sódio no solo.

Na maioria das espécies a acumulação de sódio obedece à seguinte ordem: raízes, caule, folhas. Sua mobilidade no floema é grande (principalmente em halófitas) e suas funções não são bem conhecidas. Alguns indícios de funções do $\mathrm{Na}^{+}$ são acúmulo do ácido oxálico, substituição do potássio, abertura estomatal e regulação da redutase do nitrato. Aceitase de modo geral, que, dependendo da planta, o $\mathrm{Na}^{+}$pode substituir parcialmente $\mathrm{o} \mathrm{K}^{+}$, talvez em reações enzimáticas, onde não haja exigência absoluta de $\mathrm{K}^{+}$e, possivelmente, nos seus efeitos puramente osmóticos (MALAVOLTA, 1980).

Quanto ao efeito dos ciclos na produtividade do capim Mombaça, foi observado que o segundo ciclo apresentou produção de massa verde da parte aérea e massa seca da parte aérea superior ao primeiro ciclo em todas as doses. Nas doses $0,20,40$ e $60 \mathrm{mg} \mathrm{dm}^{-3}$ de $\mathrm{Na}^{+}$em substituição ao $\mathrm{K}^{+}$, o aumento foi de 41, 48, 55 e 54\% e 31, 43, 47 e 50\% para MVPA e MSPA, respectivamente. Isso ocorreu porque no segundo ciclo o efeito da salinidade ocasionada pelo $\mathrm{Na}^{+}$no solo foi reduzido com a extração do nutriente pela planta no primeiro ciclo. Além disso, a disponibilização de energia para a formação do sistema radicular certamente foi bem menor que no primeiro ciclo e, conseqüentemente, mais energia tornou-se disponível para o desenvolvimento da parte aérea da planta (CONSOLMAGNO NETO et al., 2007).

$\mathrm{O}$ aumento dos teores de sódio no solo provoca a redução do desenvolvimento vegetal em função dos desequilíbrios nutricionais provocados pelo excesso de sais na absorção e transporte de nutrientes (FERREIRA et al., 2001; CAVALCANTE et al., 2010). Além disso, a salinidade reduz a atividade dos íons em solução e altera os processos de absorção, transporte, assimilação e distribuição de nutrientes na planta afetando a produção de biomassa (FARIAS et al., 2009). Neste sentido, Farias et al. (2009) verificaram reduções nos teores de $\mathrm{N}, \mathrm{P}, \mathrm{K}, \mathrm{Ca}, \mathrm{Mg}$ e $\mathrm{S}$ nas raízes e folhas de Gliricídia em solução nutritiva contendo $\mathrm{NaCl}$, e indicaram que há possível inibição competitiva destes nutrientes com a adição de $\mathrm{NaCl}$ na solução nutritiva. Contudo, o grau ou a concentração de sais que determinam essa redução varia com a espécie, podendo esse fato estar relacionado com a tolerância de cada espécie à salinidade (FERREIRA et al., 2001).

Para o número de perfilhos, o aumento das doses de $\mathrm{Na}^{+}$ em substituição ao $\mathrm{K}^{+}$na adubação do capim Mombaça promoveu decréscimo linear na emissão de perfilhos pela planta em ambos os ciclos de pastejo (Figura 4). As doses de 20, 40 e $60 \mathrm{mg} \mathrm{dm}^{-3}$ de $\mathrm{Na}^{+}$foram responsáveis pelas reduções de 9,6, 14,5 e 19,4\% no primeiro ciclo e 5,9, 7,8 e $11,8 \%$ no segundo ciclo, respectivamente. O mesmo comportamento foi observado por Melo et al. (2006) trabalhando com seleção de genótipos de arroz tolerantes a salinidade durante a fase vegetativa, que observaram efeito negativo em função do aumento do teor de $\mathrm{Na}^{+}$na adubação sobre o perfilhamento das plantas.

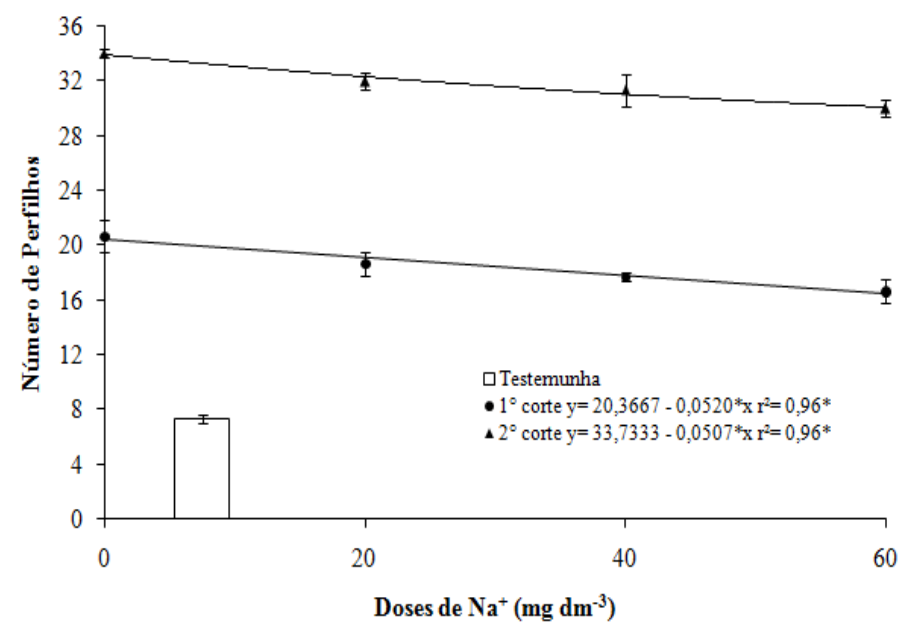

Figura 4. Número de perfilhos de capim Panicum maximum cv. Mombaça em função da substituição parcial do Potássio $\left(\mathrm{K}^{+}\right)$ pelo Sódio $\left(\mathrm{Na}^{+}\right)$em ciclos de pastejo. Gurupi-TO, 2013 
Quanto ao efeito dos ciclos de pastejo no número de perfilhos, foi observado que o segundo ciclo apresentou produção superior ao primeiro em todas as doses (Figura 4). Esse fato deve estar relacionado com o maior direcionamento de energia para o estabelecimento da planta no primeiro ciclo, com a formação de sistema radicular mais vigoroso. No segundo ciclo, a planta já tinha seu sistema radicular bem formado, necessitando provavelmente de menor quantidade de energia para a formação de raízes e aumentando a sua capacidade de emissão de perfilhos com consequente aumento na produção de forragens. Outra possível explicação é que o ciclo que simula justamente o pastejo de animais tenha quebrado a dominância apical, promovendo indução das gemas basais e, consequentemente, aumentando a emissão de perfilhos (CONSOLMAGNO NETO et al., 2007).

A adubação com sódio tem por tendência diminuir o potencial osmótico, havendo a necessidade da planta em utilizar mais energia para o processo de absorção, o que, talvez, pode alterar o processo de rebrota, já que sua energia estaria não só sendo usada para a respiração e para o crescimento (BRENNECKE et al., 2007).

A substituição do $\mathrm{K}^{+}$por $\mathrm{Na}^{+}$na adubação pode ser feita para essa forrageira, contudo, atenção deve ser mantida para o monitoramento da salinidade do solo. E mesmo, os resultados mostrando baixa redução na produção da forragem na condição de alta porcentagem de substituição de $\mathrm{K}^{+}$por $\mathrm{Na}^{+}$, sugere-se trabalhos com menores substituições até $\mathrm{O}$ desenvolvimento de pesquisas definidas elucidando os mecanismos nutricionais e de tolerância adotadas por essa forrageira. Nesse sentido, é sugerido o desenvolvimento de pesquisas na linha de partição do sódio na planta, potencial de bioacumulação, disponibilidade no solo e interação com

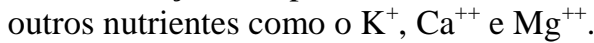

\section{CONCLUSÕES}

1. O segundo ciclo de pastejo proporciona maiores médias nos indicadores índice de clorofila, número de perfilhos, massa verde da parte aérea e massa seca da parte aérea no capim Mombaça quando comparado ao primeiro ciclo.

2. A substituição do $\mathrm{K}^{+}$por $\mathrm{Na}^{+}$na adubação aumenta a produção de forragem até a dose de $28,77 \mathrm{mg} \mathrm{dm}^{-3} \mathrm{de} \mathrm{Na}^{+}$a partir dos 60 dias de emergência das plantas.

3. A substituição do $\mathrm{K}^{+}$por $\mathrm{Na}^{+}$na adubação reduz em $7,9 \%$ o desenvolvimento do capim Mombaça.

\section{REFERÊNCIAS BIBLIOGRÁFICAS}

ARAGÃO, R. M.; SILVEIRA, J. A. G.; SILVA, E. N.; LOBO, A. K. M.; DUTRA, A. T. B. Absorção, fluxo no xilema e assimilação do nitrato em feijão-caupi submetido à salinidade. Revista Ciência Agronômica, Fortaleza, v.14, n.1, p.100-106, 2010.

BRENNECKE, K.; SILVA, N. M. A.; MACIEL, J. C.; BOAS, W. S. V.; RODRIGUES, R. C.; LIMA C. G.; LACERDA, R. S.; FERRAZ, M. R. Efeitos de doses de sódio e nitrogênio na digestibilidade "in vitro" do capim Coastcross (Cynodon dactylon (1.) pers.), em duas idades de corte no verão de 2001/02. Boletim de Indústria Animal, N. Odessa, v.64, n.3, p.185-190, 2007.
CANTARUTTI, R. B.; MARTINS, E. C.; CARVALHO, M. M.; FONSECA, D. M.; ARRUDA, M. L.; VILELA, H.; OLIVEIRA, F. T. T. Pastagens. In: Comissão de fertilidade do solo do estado de Minas Gerais recomendações para uso de corretivos e fertilizantes em Minas Gerais - $5^{\circ}$ Aproximação. Viçosa: UFV, 1999. p.322.

CAVALCANTE, L. F.; CORDEIRO, J. C.; NASCIMENTO, J. A. M.; CAVALCANTE, I. H. L.; DIAS T. J. Fontes e níveis da salinidade da água na formação de mudas de mamoeiro cv. Sunrise solo. Semina: Ciências Agrárias, Londrina, v.31, suplemento.1, p.1281-1290, 2010.

DANTAS, J. A.; NETO, E. B.; BARRETO, L. P.; SANTOS, M. V. F. Efeito da salinidade sobre o crescimento e composição mineral de seis clones de Pennisetum. Revista Ciência Agronômica, Ceará, v.37, n.1, p.97101, 2006.

DUARTE, I. N.; SOUSA, R. T. X.; KORNDORFER, G. H.; FONTOURA, P. R.; SOARES, R. A. B. Biotita: fonte de potássio para agricultura. Bioscience Journal, Uberlândia, v.28, suplemento.1, p.98-103, 2012.

EICHLER, V.; SERAPHIN, E. S.; PORTES, T. A.; ROSA, B.; ARAÚJO, L. A.; SANTOS, G. Produção de massa seca, número de perfilhos e área foliar do capimmombaça cultivado em diferentes níveis de nitrogênio e fósforo. Ciência Animal Brasileira, Goiânia, v.9, n.3, p.617-626, 2008.

EMPRESA BRASILEIRA DE PESQUISA AGROPECUÁRIA (EMBRAPA). Centro Nacional de Pesquisa de Solos. Sistema Brasileiro de Classificação de Solos. Rio de Janeiro, 2006.

ERNANI, P. R.; ALMEIDA, J. A.; SANTOS, F. C. Potássio. In: NOVAIS, R. F.; ALVAREZ, V. H.; BARROS, N. F.; FONTES, R. L. F.; CANTARUTTI, R. B.; NEVES, J. C. L. (ed) Fertilidade do Solo. Viçosa: UFV, 2007. p.551594.

FARIAS, S. G. G.; SANTOS, D. R.; FREIRE, A. L. O.; SILVA, R. B. Estresse salino no crescimento inicial e nutrição mineral de Gliricídia (Gliricidia sepium (Jacq.) Kunt ex Steud) em solução nutritiva. Revista Brasileira de Ciência do Solo, Viçosa, v.33, n.5, p.1499-1505, 2009.

FERNANDES, A. R.; CARVALHO, J. G.; CURI, N.; GUIMARÃES, P. T. G.; PINTO, J. E. B. P. Crescimento de mudas de pupunheira (Bactris gasipaes h.b.k) sob diferentes níveis de salinidade. Ciência e Agrotecnologia, Lavras, v.27, n.2, p.278-284, 2003.

FERREIRA, R. G.; TÁVORA, F. J. A. T.; HERNANDEZ, F. F. F. Distribuição da matéria seca e composição química das raízes, caule e folhas de goiabeira submetida a estresse salino. Pesquisa Agropecuária Brasileira, Brasília, v.36, n.1, p.79-88, 2001. 
HOHJO, M.; GANDA, M.; MARUO, T.; SHINOHARA, Y.; ITO, T.; MALOUPA, E.; GERASOPOULOS, G. Effects of $\mathrm{NaCl}$ application on the growth, yield and fruit quality in NFT-tomato plants. Acta Horticulturae, Grécia, v.548, n.55, p.469-475, 2001.

LACERDA, C. F.; CAMBRAIA, J.; OLIVA, M. A.; RUIZ, H. A.; PRISCO, J. T. Solute accumulation and distribution during shoot and leaf development in two sorghum genotypes under salt stress. Environmental and Experimental Botany, v.49, n.2, p.107-120, 2003.

LACLAU，J.; RANGER，J.; BOUILLET，J.; NIZLA，J.; DELEPORTE, P. Nutrient cycling in a clonal stand of Eucalyptus and an adjacent savana ecosystem in Congo. 1. Chemical composition of rainfall. Troughfall and stemflow solutions. Forest Ecology and Management, v.176, n.1, p.105-119, 2003.

LOPES, A. S. Reservas de minerais potássicos e produção de fertilizantes potássicos no Brasil. In: Yamada, T.; Roberts, T. L. (eds). Potássio na agricultura brasileira. Piracicaba: Brasil, 2005. p.21-32.

MALAVOLTA, E. Elementos de nutrição mineral de plantas. São Paulo: Ceres. 1980. 251p.

MARSCHNER, H. Mineral nutrition of higher plants. London: Academic Press, 1995. 889p.

MELO, P. C. S.; ANUNCIAÇÃO FILHO, C. J.; OLIVEIRA, F. J.; BASTOS, G. Q.; TABOSA, J. N.; SANTOS, V. F.; MELO, M. R. C. S. Seleção de genótipos de arroz tolerantes a salinidade durante a fase vegetativa. Ciência Rural, Santa Maria, v.36, n.1, p.58-64, 2006.

NETO, D. C.; MONTEIRO, F. A.; DECHEN, A. R. Características produtivas do capim Tanzânia cultivado com combinações de potássio e de magnésio. Acta Scientiarum Agronomy, Maringá, v.29, n.4, p.459-467, 2007.

OHTA, D.; MATOH, T.; TAKAHASHI, E. Early responses of sodium-deficient Amaranthus tricolor L. plants to sodium application. Plant Physiology, v.84, n.1, p.112117, 1987.

ROMERO, R. R. Resposta fisiológica de plantas de Eucalyptus grandis à adubação com potássio ou sódio. Piracicaba: Universidade de São Paulo, 2008. 57p. Dissertação de mestrado.

SILVA, D. F.; MATOS, A. T.; PEREIRA, O. G.; CECON, P. R.; MOREIRA D. A. Disponibilidade de sódio em solo com capim tifton e aplicação de percolado de resíduo sólido. Revista Brasileira de Engenharia Agrícola e Ambiental, Campina Grande, v.14, n.10, p.1094-1100, 2010.

SILVA, E. N.; SILVEIRA, J. A. G.; FERNANDES, C. R. R.; DUTRA, A. T. B.; ARAGÃO, R. M. Acúmulo de íons e crescimento de pinhão-manso sob diferentes níveis de salinidade. Revista Ciência Agronômica, Fortaleza, v.40, n.2, p.240-246, 2009.
SULTANA, N.; IKEDA, T.; ITOH, R. Effect of $\mathrm{NaCl}$ salinity on photosynthesis and dry matter accumulation in developing rice grains. Environmental and Experimental Botany, v.42, n.2, p.211-220, 1999.

TALBOTT, L.; ZEIGER, E. The role of sucrose in guard cell osmoregulation. Journal Experimental Botany, v.49, ed. especial, p.329-337, 1998.

VILLORA, G.; PULGAR, G.; MORENO, D.; ROMERO, L. Salinity treatments and their effect on nutrient concentration in Zucchini plants (Cucurbita pepo L. var. Moschata). Australian Journal of Experimental Agriculture, v.37, n.5, p.605-608, 1997.

YAMADA, T.; ROBERTS, T. L. Potássio na Agricultura Brasileira. Piracicaba: Associação Brasileira da Potassa e do Fosfato, 2005. 841p.

ZHANG, Y.; LI, Q.; ZHOU, X.; ZHAI, C.; LI, R. Effects of partial replacement of potassium by sodium on cotton seedling development and yield. Journal of Plant Nutrition, v.29, n.10, p.1845-1854, 2006. 